\title{
CURRÍCULO MULTICULTURAL DECOLONIAL: tensões e desafios em uma tessitura docente
}

\author{
Fabiano Lange Salles \\ Departamento de Educação Física, Colégio Pedro II - CPII, Brasil
}

Ana Ivenicki

Universidade Federal do Rio de Janeiro - UFRJ, Brasil

\begin{abstract}
Resumo
Ao assumirmos a escola como um espaço de cruzamentos culturais, argumentamos que construções curriculares responsivas à complexidade da dinâmica escolar podem se beneficiar de perspectivas multiculturais decoloniais que desafiem a fixidez de sentidos no currículo e valorizem a pluralidade cultural. A partir dessas premissas, o presente artigo discute o currículo multicultural decolonial e analisa o caso de uma construção curricular da disciplina Educação Física no Colégio Pedro II, focalizando especificamente as negociações multiculturais empreendidas no decorrer dessa trajetória, bem como desdobramentos de tal processo no texto curricular produzido e nos possíveis impactos multiculturais nas identidades docentes participantes desse percurso. Os resultados podem contribuir para a discussão sobre tensões e possibilidades em tentativas de tradução da perspectiva decolonial do currículo multicultural em processos de tessitura curricular que envolvem identidades docentes enquanto comunidades de aprendizagem docente, multiculturalmente orientadas.
\end{abstract}

Palavras-chave: Formação continuada; Multiculturalismo; Perspectivas decoloniais; Construção curricular; Educação Física.

\begin{abstract}
The present paper argues that school is a space of cultural exchanges and that decolonial multicultural perspectives could help build a curriculum responsive to that complexity, because such perspectives challenge fixed meanings of curriculum and value cultural diversity. Based on that, the paper discusses decolonial multicultural curriculum, and it analyses the case of a curriculum construction of Physical Education in the school Colégio Pedro II, focusing specifically on the cultural exchanges that took place during the process, as well as the implications of such a process both in the curricular text produced, and in the teachers' identities who took part in the study. Results should hopefully contribute to the discussion about tensions and possibilities of experiences that try to translate decolonial multicultural curricular perspectives into actual curriculum construction that engage teachers' identites as multiculturally oriented learning communities.
\end{abstract}

Keywords: Continuing teacher education; Multiculturalism; Decolonial perspectives; Curriculum construction; Physical Education. 


\section{Introdução}

A diversidade cultural presente no contexto escolar confirma a ideia defendida por autores (CANDAU, 2012; MOREIRA \& CANDAU, 2011; IVENICKI, 2018) de que vivemos em sociedades multiculturais e de que a escola, dentro desse contexto, representa um espaço de cruzamentos culturais. Tal ideia implica na construção de um currículo que valorize as identidades culturais por meio da negociação cultural, dando voz às culturas silenciadas, combatendo discursos preconceituosos e transformando a escola num espaço de problematização e produção cultural.

Pensar no currículo no âmbito do ensino superior e, mais especificamente, na formação de professores implica, pois, em reconhecer seu impacto na formação das identidades docentes, enfatizando-se seu potencial para promover a valorização da diversidade cultural e desafiar o racismo, as desigualdades, os preconceitos e os silenciamentos de vozes de grupos subalternizados, em função de raça, etnia, gênero e outros marcadores identitários (CANDAU, 2012; IVENICKI; XAVIER, 2017; IVENICKI, 2018; JANOÁRIO, 2018; LOPES; OLIVEIRA; OLIVEIRA, 2018; MACEDO, 2006).

Nessa perspectiva, buscam-se possibilidades de currículo concebido multiculturalmente como espaço de diferenciação e de valorização da alteridade (IVENICKI, 2018; MACEDO, 2006; MILLER, 2019). Argumentamos que perspectivas decoloniais no currículo têm contribuído para o desafio a saberes pseudouniversais que são, na verdade, produzidos por grupos culturais hegemônicos, atravessados por valores eurocêntricos (CANDAU, 2019). De fato, perspectivas decoloniais têm contribuído para alargar a perspectiva multicultural, uma vez que buscam problematizar conhecimentos hegemônicos, eurocêntricos e colonialistas. Miranda (2019) propõe que agendas curriculares decoloniais apresentam cartografias em que as identidades de gênero, etnicorraciais e de grupos subalternizados passam a ser centrais para a construção do conhecimento, nas diversas áreas. Desse modo, tais perspectivas decoloniais contribuem para a desconstrução de imagens estereotipadas e de inferiorização de identidades marginalizadas, visões ligadas à colonialidade dos saberes curriculares. Dessa forma, perspectivas decoloniais no currículo multiculturalmente concebido desmascaram as origens das visões hegemônicas sobre identidades raciais, de gênero e outras e propõem a formação de professores e de futuras gerações nos valores da pluralidade e da construção curricular para a diversidade cultural.

A partir do exposto, voltaremos os nossos olhares para uma experiência de construção curricular da disciplina Educação Física do Colégio Pedro II, que se caracterizou também como um espaço de formação continuada que, numa dimensão mais endógena de aprendizagem docente pode ser compreendida como experiências de aprendizado implementadas por professores/as que, ao se deparem com demandas e desafios do cotidiano escolar criam espaços de estudo, reflexão e desenvolvimento de encaminhamentos pedagógicos para o enfrentamento mais maduro desses desafios. Ao enfocarmos o processo de construção curricular e aprendizagem docente, também buscaremos analisar as possíveis ressonâncias multiculturais no documento curricular e nas identidades docentes que participaram dessa trajetória. 
A relevância do estudo dá-se na medida em que, conforme Ranniery e Macedo (2018), as ações cotidianas, escorregadias, invisíveis, têm se constituído em novos modos de vida política, em espaços que abrem escolas e currículos à diferença, representando o que denominam de "cenas curriculares", em contraposição a efeitos universalizantes e, muitas vezes, homogeneizadores de políticas mais amplas curriculares.

\section{O currículo multicultural decolonial: reflexões}

O currículo da escola é resultado de atividades de ensino que definem o que pode ser representado ou não, legitimado e deslegitimado. Os discursos contidos nele, de forma clara ou subentendida, apresentam conceitos particulares sobre o conhecimento, sobre formas de se organizar uma sociedade e os diferentes grupos sociais. Dentro dessa perspectiva, o currículo, além de ser uma prática que atribui significados, é um discurso que constrói sentidos. "Ele é, portanto, uma prática cultural" (LOPES; MACEDO, 2011, p. 203).

Intrínsecas a esse compartilhamento de sentidos e significados estão as relações de poder em que cada grupo social e identidades entram em disputa para legitimar suas visões de mundo, suas representações. Por isso, o currículo da escola contempla representações produzidas por grupos sociais com base em suas identidades, que, ao mesmo tempo, formam novas identidades por meio da produção de significados. Assim, o currículo pode ser visto como prática de significação (LOPES; MACEDO, 2011; SILVA, 2011). Esse ciclo de relações se estabelece no cotidiano escolar, muitas vezes de forma naturalizada e acrítica, privilegiando culturas, temas e identidades sociais em detrimento de outras.

Ao mesmo tempo, o multiculturalismo é geralmente compreendido como um conjunto de situações didáticas que articulam teoria e ações práticas para a melhoria das vidas de grupos marginalizados (MOREIRA; CANDAU, 2011; IVENICKI, 2018; JANOÁRIO, 2018). É importante sinalizar que o multiculturalismo contempla um espectro que vai de abordagens mais liberais e folclóricas, nas quais se valorizam ritos, datas comemorativas e outros aspectos das identidades plurais, até perspectivas mais críticas, pós-coloniais e decoloniais do currículo, que enfatizam a necessidade de se desafiar preconceitos e relações de poder desiguais que prejudicam identidades sexuais, de gênero, étnico-raciais e outros grupos marginalizados, defendendo hibridizações e problematizando a construção discursiva dos estereótipos (IVENICKI, 2018; IVENICKI; XAVIER, 2017), bem como a fixação de discursos identitários em políticas curriculares (MACEDO, 2006). É relevante destacar que processos de colonização e políticas contemporâneas, que ainda se imbuem dessas perspectivas, operam em termos de controle e negação do pluralismo.

Nesse sentido, abordagens curriculares multiculturais decoloniais problematizam currículos baseados em perspectivas hegemônicas em detrimento da valorização dos saberes nativos de grupos subalternizados. É importante sinalizar que tais perspectivas decoloniais no currículo têm contribuído para o desafio a saberes pseudouniversais que são, na verdade, produzidos por grupos culturais hegemônicos, atravessados por valores eurocêntricos. 
Conforme Candau (2019), a colonialidade do conhecimento vai além dos processos políticos de colonização que sociedades enfrentaram. Ainda que tais processos tenham findado com a independência das ex-colônias, a colonialidade dos saberes se reflete nas perspectivas curriculares que valorizam as culturas daquelas metrópoles, em detrimento do conhecimento produzido por identidades marginalizadas de gênero, raça, classes sociais e outras, locais, nativas. A referida autora propõe uma articulação entre os conceitos de multi/interculturalismo crítico e perspectivas decoloniais, argumentando que podem fertilizar-se mutuamente ao valorizarem a diversidade cultural, desafiarem preconceitos e, ao mesmo tempo, trazerem, para o centro do currículo, o questionamento a saberes hegemônicos e colonialistas.

Macedo (2006) e Miller (2019), em perspectivas curriculares pós-estruturalistas e póscríticas, têm contribuído para tais reflexões, alertando para os perigos de fixação de sentidos em propostas e políticas de currículo. A essencialização curricular e a hegemonia de saberes ocidentalizados e eurocêntricos, a fixação de sentidos do currículo e o congelamento das identidades constituem-se em marcas de colonialidade dos saberes que devem ser desnaturalizadas, questionadas e problematizadas.

Tais considerações podem enriquecer processos de formação continuada, favorecidos por movimentos coletivos de construção curricular. A formação continuada dentro de uma perspectiva multicultural decolonial pode ser importante alternativa na sensibilização dos profissionais de educação para a valorização da pluralidade cultural como princípio fundamental nas construções curriculares e, por consequência, para a constituição de uma escola culturalmente responsiva (IVENICKI, 2018).

Cochran-Smith e Lytle (2002) apresentam uma dimensão de aprendizagem de professores que se dá na concepção do conhecimento da prática em que se entende que a formação docente se constitui ao longo da vida, tendo como espaço privilegiado dessa formação a escola. Nessa concepção, o conhecimento não está separado do sujeito que conhece, pois se entende que o conhecimento é produzido no contexto do seu uso. O pressuposto básico dessa perspectiva é que professores, ao longo de sua vida profissional, têm um papel central e crítico na construção do conhecimento sobre a prática, na medida em que as salas de aula são potenciais locais de investigação e que, associadas às questões mais amplas, podem assumir uma perspectiva crítica.

$\mathrm{Na}$ concepção do conhecimento da prática, o aprendizado de professores está relacionado a esforços mais amplos que pressupõem mudanças na organização escolar com vistas a uma escola democrática e mais justa socialmente. $\mathrm{O}$ desafio a perspectivas universalizantes e colonialistas do currículo, em processos de construção curricular coletivos, pode representar espaços multiculturais decoloniais relevantes na formação continuada docente, rumo à transformação educacional. 


\section{A tessitura curricular: aspectos metodológicos e início do trabalho}

Conforme Candau (2019), a pesquisa multicultural em perspectiva decolonial implica que sujeitos e objetos do estudo não podem ser considerados como polos estanques, mas, ao contrário, estão simbioticamente articulados, de modo que as relações de colonialidade do saber e do poder sejam desafiadas em relações dialógicas, multiculturais, no decorrer de todo o estudo. Ivenicki (2018), na mesma perspectiva, aponta que pesquisas multiculturalmente orientadas valorizam tanto as identidades individuais presentes no campo em estudo quanto as identidades coletivas (de pertencimento a marcadores de raça, etnia, orientação sexual, gênero e outras) e as identidades institucionais (relativas aos projetos político-pedagógicos das instituições em estudo, assim como o clima institucional e as histórias delas).

Nesse sentido, em termos do campo empírico da pesquisa em tela, o Colégio Pedro II apresenta-se como identidade institucional que carrega o peso da tradição e, ao mesmo tempo, busca empreender ações institucionais e curriculares valorizadoras da diversidade de identidades sexuais, de gênero, de raça, entre outras. Realizamos, naquele espaço, uma pesquisa de cunho qualitativo (DESLANDES, 2012), que se caracterizou como um estudo de caso que consiste na investigação de um fenômeno atual dentro de seu cenário da vida real e que permite uma análise profunda de uma ou poucas unidades, por exemplo uma comunidade ou uma instituição, de forma que possibilite seu amplo e detalhado conhecimento do objeto de estudo (YIN, 2001; GIL, 2002). Ao assumimos as limitações enfrentadas em pesquisar um objeto de estudo fruto de uma experiência da qual um dos autores do presente artigo fez parte, enquanto coordenador, enfatizamos o exercício do rigor metodológico ao empreender a multiplicidade ou triangulação de métodos, uma importante alternativa para a validação da pesquisa, e garantia de "uma compreensão em profundidade do fenômeno em questão" (DENZIN; LINCOLN, 2010 p. 19).

Assim, a triangulação de métodos deu-se na medida em que os 25 encontros para a elaboração curricular, que ocorreram entre 7 de abril de 2016 e 7 de abril de 2017, foram registrados pelo gravador de voz do celular Samsung Galaxy S7® e o gravador de voz mp3 da marca Sony® e geraram mais de 71 horas de áudio, as quais foram totalmente transcritas, além das conversas realizadas entre os participantes, ao longo desse período, por meio de endereços eletrônicos, Facebook e pelo aplicativo WhatsApp.

Com vistas ao aprofundamento da análise do fenômeno estudado e enfatizarmos a triangulação, empreendemos a análise documental do currículo prescrito, criado pelo grupo de professores (COLÉGIO PEDRO II, 2017), produto do processo de formação continuada em tela. Para a análise dos dados, utilizamos o método de interpretação dos sentidos que, segundo Gomes (2010, p. 105), propõe um avanço nesse processo, indo além dos conteúdos de textos "[...] na direção de seus contextos e revelando as lógicas e as explicações mais abrangentes presentes numa determinada cultura acerca de um determinado tema".

Realizamos também entrevistas semiestruturadas com seis dos 21 participantes da tessitura curricular, que "[...] combinam perguntas fechadas e abertas, em que o entrevistado tem a possibilidade de discorrer sobre o tema em questão sem se prender à indagação formulada" (MINAYO, 2010, p. 64). A escolha dos professores e professoras para a 
entrevista se baseou nos critérios de diferentes tempos na instituição, de docentes mais frequentes nos encontros, que trabalhavam em campi diferentes e em diversos níveis de ensino.

Conforme percebido, trata-se de uma pesquisa abrangente, cuja produção de dados durou, conforme explicitado, cerca de um ano e gerou mais de 71 horas de gravações de áudio. O presente estudo é um fragmento desse trabalho, abarcando as negociações multiculturais empreendidas no decorrer da construção curricular entre os sujeitos da pesquisa, bem como os desdobramentos de tal processo no texto curricular produzido. Por isso, nos limites do presente estudo, enfocamos aspectos que consideramos potentes dessa trajetória de tessitura curricular enquanto processo de formação continuada multiculturalmente orientado, a partir de diálogos empreendidos nos encontros desenvolvidos, do texto curricular produzido e das entrevistas realizadas, buscando perceber as ressonâncias multiculturais decoloniais nas identidades docentes participantes desse percurso.

A participação das diferenças foi um princípio-base da primeira fase de tessitura curricular, pois precisávamos minimizar os riscos de "engavetamento" do documento que iríamos elaborar, caso fosse produzido por poucas pessoas, assim como reconhecíamos a necessidade de construir o currículo mais plural e representativo possível, dentro da visão multicultural decolonial que abraçamos (CANDAU, 2019; IVENICKI, 2018) e coerentes com sensibilidades pós-estruturais e pós-críticas (MACEDO, 2006; RANNIERY; MACEDO, 2018; MILLER, 2019).

Para tanto, inicialmente, foi feito um convite amplo e irrestrito a todos os professores de Educação Física da escola. Contudo, precisamos lançar mão de uma ação específica, que foi o convite pessoal aos grupos de professores cujas equipes eram consideradas politicamente dissidentes da Chefia de Departamento, como podemos ver na mensagem pessoal enviada a um dos professores:

Eu, particularmente, gostaria muito de ver [vocês] [...] participando do grupo porque sei o quanto podem contribuir. Também, sei das questões políticas que envolvem a relação do $\mathrm{DEF}^{1}$ com [a equipe], mas entendo, também, que esse é um momento em que as diferenças que nos afastam devem ser superadas pelas diferenças que nos aproximam. Por isso, reitero o convite a vocês!! (Coordenador/pesquisador, Messenger do Facebook, 5/4/2016).

Escolhemos fazer um convite mais incisivo por entendermos que, se não o fizéssemos, seria muito mais difícil garantir presença desses professores no grupo, por eles guardarem profundas divergências com a Chefia de Departamento. Desde o início da idealização do Grupo de Trabalho para a construção curricular, ressaltou-se a importância de termos, nesse processo de tessitura curricular, a participação de todos os professores, sem distinção, incluindo os diferentes "mais diferentes" de nós. Do contrário, seríamos incoerentes com um dos princípios basilares da construção curricular multicultural decolonial, que foi a inclusão das diferenças. 
Ao valorizar a presença de todos os professores e professoras da disciplina Educação Física nesse fórum de debate, não estava em questão o quanto esse ou aquele pensava diferente de nós. O único interesse que nos unia era a elaboração curricular, independente das afinidades entre os colegas, por isso foi possível colocar antigos adversários para sentar juntos e debaterem temas de interesse comum. Para nós, o currículo, desde sua constituição, deveria ser uma esfera pública em que todos teriam direitos semelhantes de atuação, um local onde os sujeitos teriam a oportunidade de exercer suas habilidades para discussão, participação e para o questionamento dos pressupostos do senso comum da vida social (SILVA, 2011). Por isso, utilizamos diversas ações que garantissem a participação das diferenças nesse fórum de construção curricular, permitindo contribuir para a pluralidade de visões sobre as temáticas abordadas e, consequentemente, para a constituição de identidades docentes mais sensíveis à diversidade cultural e questionadoras de saberes hegemônicos e da fixidez de sentidos curriculares (IVENICKI, 2018; MACEDO, 2006; MILLER, 2019).

Ao final do período de convite aos professores, conseguimos reunir um grupo de 21 docentes com experiência em todas as etapas da Educação Básica, desde a educação infantil até o ensino médio, e que trabalhavam na maioria dos campi do Colégio Pedro II.

Defendemos a ideia de que a experiência de tessitura curricular em tela transformou-se numa extensa experiência de aprendizagem docente que se deu ao longo de doze meses num percurso rico de estudos e reflexões, conflitos e consensos, divergências e convergências que contribuíram para a sensibilização dos participantes no sentido de valorizarem a pluralidade cultural e, por consequência, para atuarem de forma coerente com o contexto plural inerente à escola, ainda que, em seções posteriores, sejam mostrados os desafios e as tensões políticoepistemológicas no processo.

\section{Dados do campo: a construção curricular nas diferenças}

O processo de tessitura curricular na nossa comunidade de aprendizagem docente contou com a elaboração do seu currículo interno, pois, para operacionalizarmos a construção do documento, inicialmente havia um entendimento do coordenador de que precisaríamos nos preparar por meio da leitura, estudo e debate de alguns textos. Assim, a gênese da nossa comunidade de aprendizagem docente se dá a partir das respostas às perguntas que, segundo Silva (2011), nenhum currículo pode fugir: o que deveríamos saber? Que conhecimentos seriam importantes, "válidos", para merecerem ser considerados parte do currículo? Buscamos responder a essas perguntas ao pensar em bibliografias relevantes para a elaboração curricular, ao mesmo tempo abrindo espaço aos participantes para a proposição de outros textos. Nesse contexto, a professora Kelly ${ }^{2}$ fez a seguinte afirmação:

Gosto muito deste livro aqui [aponta um livro chamado Educação Física Currículo e Cultura, de Neira e Nunes, 2009]. Em especial, o quinto capítulo [...], esse aí que tá marcado, e é um dos melhores... (Kelly). 
Esse aqui, digamos assim, é basilar [...]. Ok, acho que já é uma sugestão, pra mim, ótima (Coordenador/pesquisador, 28/4/2016).

Inicialmente, o texto foi aceito por todos e incluído nos nossos debates ao longo dos encontros seguintes. No entanto, diante de outro debate acerca das perspectivas curriculares que os textos escolhidos conduziam, outro professor demonstrou certo incômodo pela ênfase na perspectiva pós-crítica da Educação Física, como podemos ver a seguir:

Eu acho que a gente tá perdendo o caminho, certo? Por conta de estar tentando estudar uma linha ou tentando fazer com que as pessoas estudem essa linha. As pessoas não têm esse tempo [...] eu queria esclarecer que foi o coordenador/pesquisador que produziu a estimulação deste livro aqui [aponta o livro de Neira e Nunes, 2009] [...]. Isso não deveria ser discutido nesse tom. Aliás, essa é minha fala (Reginaldo).

[...] se a gente entender que precisa estudar cada uma das tendências, é legal porque eu tenho certeza que cada um de nós viveu cada uma dessas tendências [...], mas, se a gente entender que a gente precisa voltar atrás, rever, pensar em outra proposta, que o multiculturalismo não atende, que o outro atende, a gente vai fazer isso aqui, mas isso só é possível se a gente estiver todo mundo junto aqui mesmo discutindo (Jordana).

[...] quando você [Reginaldo] fala que a gente não quer estudar uma teoria, eu queria que a gente fizesse uma autoavaliação do quanto eu me sinto incomodado com teorias que eu não abraço, então isso é uma coisa que a gente precisa rever, porque, assim, eu estou aberto às teorias [...] (Coordenador/pesquisador, 12/5/2016).

As resistências às teorias pós-críticas ficaram aparentes no comentário acima em virtude da interpretação do professor Reginaldo de estarmos valorizando o texto que enfatizava a perspectiva pós-crítica da Educação Física, em detrimento de outras. Pelo decorrer do debate, percebemos que os interlocutores buscaram ponderar a flexibilidade para se abordar todas as perspectivas curriculares, assim como a necessidade de os professores estarem abertos a conhecer perspectivas novas, mesmo que essas não fossem as que eles defendiam. Dessa forma, podemos inferir que experiências de construção curricular, no contexto de uma comunidade de aprendizagem docente multiculturalmente orientada, precisam ser permeadas pela negociação cultural, que defende o reconhecimento do "outro" e empreendem diálogos entre diferentes grupos identitários (CANDAU, 2012).

A leitura coletiva da primeira versão do currículo se constituiu num tempo-espaço privilegiado de aprendizagem docente, na medida em que cada leitura impactava as identidades docentes. Uma dessas experiências deu-se ao lermos um dos objetivos do currículo que propunha "[...] questionar os discursos normativos e ressignificar a maneira de ver os temas abordados e as intencionalidades presentes nas estratégias pedagógicas”. Ao 
lermos esse trecho, a professora Clarissa perguntou: o que são “discursos normativos?”. A partir desse questionamento, iniciamos o seguinte diálogo:

Discursos normativos são aqueles que são cristalizados e naturalizados como norma (Coordenador/pesquisador).

"Menina só veste rosa", "menino joga futebol melhor" (Kelly).

"Menino é mais forte", ou "se a menina é mais fraca, ela não vai para o gol". "Só menino pode entrar no gol". Isso foi a discussão do ano passado [sobre os Jogos Intercampi ${ }^{3}$ ] (Coordenador/pesquisador).

Tem uma [regra dos jogos Intercampi] que eu fiquei chocada: "quando tem empate do número de vivos no queimado, o que define qual das duas equipes que ganha é quem queimou o primeiro menino". Esse é um critério de desempate... foi a maior discussão (Jordana).

Nas nossas reuniões, a gente colocou essa questão para ele [Chefe de Departamento], nos sentindo muito incomodados com algumas das regras que colocaram no Intercampi. Ele ficou chocado, e falou assim: "gente, vamos rever", mas a gente estava a uma semana dos jogos. Mas assim, o que eu quero marcar não é o caso de rever, é como é que fomos atingindo a tua argumentação. Isso foi bacana (Silvana).

Sim, que já é fruto das discussões desse GT (Coordenador/pesquisador).

Ele não tinha parado para pensar nisso. Para ele, estava natural (Silvana).

Os próximos Jogos Intercampi precisam estar alinhados a essa proposta (Coordenador/pesquisador) (Encontro 22, quinta-feira, 16/02/2017).

Seguidamente à explicação do que se entendia por discursos normativos, alguns professores citaram exemplos que implicaram em preconceitos de gênero, reforçando uma suposta condição de fragilidade feminina. Esses discursos, presentes nas regras dos Jogos Intercampi de 2016, foram problematizados no grupo. Tal fato acabou por chamar a atenção do Chefe de Departamento (participante do nosso grupo), que, segundo a professora Silvana, considerava "naturais" as regras e que não havia "parado para pensar" que tais discursos eram sexistas. Ato contínuo, junto à equipe de professores, após constatar as nuances de discriminação presente nas regras, a chefia de departamento propôs revê-las.

Esse exemplo, a nosso ver, representa a potencialidade dos debates que se desenvolvem dentro de uma perspectiva multicultural decolonial, questionadora das relações desiguais de poder entre as identidades e problematizadora de construções históricas de preconceitos e de discursos congelados, colonialistas e normatizados (CANDAU, 2019; IVENICKI, 2018; MACEDO, 2006; RANNIERY; MACEDO, 2018; MILLER, 2019), contribuindo, assim, para sensibilizar identidades docentes com relação à forma como o currículo colonialista privilegia conhecimentos e identidades, vozes e discursos, em detrimento de outros (NEIRA; NUNES, 2009). Em consequência de debates como esses, no âmbito dessa experiência de aprendizagem docente, surgiu a necessidade de materializar tal perspectiva em um dos 
objetivos do currículo, desencadeando uma revisão das regras dos Jogos Intercampi, no sentido de identificar "discursos normativos" que resultassem em discriminação e silenciamentos de identidades para, em seguida, mudar essas regras.

É importante salientar que o primeiro ponto de ressonância de toda a trajetória de leituras, debates e reflexões foi a escrita curricular, materializada num documento composto por três seções: apresentação; ensino da disciplina nos diversos segmentos; e, por último, a seção pesquisa, extensão e cultura, dentre as quais destacaremos alguns trechos que consideramos mais relevantes para o presente artigo.

A primeira seção, denominada "apresentação", exibiu uma breve abordagem histórica do currículo da Educação Física no Colégio Pedro II, que transitou desde as perspectivas mais tradicionais até aquelas críticas, pós-críticas e decoloniais. A problematização, dentro de uma perspectiva multicultural no documento, pode ser percebida em alguns trechos dessa seção, por exemplo numa análise que o documento faz dos currículos dessa disciplina dessa instituição, entre os anos de 1981 e 1989, em que é possível ler o seguinte excerto:

A homogeneização cultural é uma das características marcantes dos planos de curso desse período. Isso pode ser constatado na unidade didática denominada "teste de aptidão física" [...]. Dentre os inúmeros objetivos desse teste, destaca-se o de "fornecer elementos para a seleção e formação de grupos homogêneos" (COLÉGIO PEDRO II, 2017, p. 234).

A crítica com relação à intencionalidade de homogeneização curricular por meio da homogeneização identitária de grupos de estudantes caracteriza o texto como multicultural, na medida em que seus autores buscam desvelar ações curriculares que preconizavam práticas monoculturais e identificavam padrões semelhantes de aptidão física para organizar grupos de estudantes. Tal tipo de ação homogeneizadora poderia gerar exclusões ou segregação de outros grupos que não se enquadrassem em padrões normatizados como "ótimos" de aptidão física.

Ainda, na seção "apresentação", após um breve relato da trajetória de construção curricular, é possível ler, no documento, o seguinte trecho:

[...] esta proposta curricular pretende estimular práticas atentas à pluralidade de identidades dos estudantes, a partir da compreensão da escola como espaço-tempo multicultural de formação, a fim de construir uma sociedade democrática e justa, finalidade primeira da educação pública (COLÉGIO PEDRO II, 2017, p. 238).

É possível perceber, a partir do excerto, a menção clara à perspectiva multicultural como balizadora para compreender a escola como um espaço de cruzamentos culturais (MOREIRA; CANDAU, 2011). Com isso, vemos, nesse trecho, indícios que nos permitem caracterizar o documento como multiculturalmente explícito, pois utilizam taxativamente o termo multi/interculturalismo como pressuposto teórico (CANEN; XAVIER, 2011). No entanto, ao considerarmos a polissemia do termo multiculturalismo, é importante sabermos sobre em quais perspectivas multiculturais o documento se embasa. No parágrafo seguinte, 
começamos a compreender a ênfase ao multiculturalismo crítico, a partir do que o discurso do documento explicitou em termos do que seria um currículo responsivo à diversidade

[...] um currículo coerente e efetivamente responsivo à diversidade, "valoriza e reconhece as diferenças, como também assegura a diversidade cultural, superando processos discriminatórios, opressão, injustiça social e naturalização das diferenças, apontando focos de resistência e de construção da identidade cultural" (NEIRA, 2015, p. 293) (COLÉGIO PEDRO II, 2017, p. 238).

As semelhanças com o multiculturalismo crítico são patentes nesse trecho, uma vez que essa perspectiva também questiona a construção histórica de discriminações, preconceitos e das diferenças presentes no currículo (IVENICKI; XAVIER, 2017).

$\mathrm{Na}$ mesma seção de "apresentação", há uma subseção denominada "fundamentação teórica”, em que se apresentam os princípios teóricos fundamentais da proposta curricular em análise. De começo, o leitor é provocado a desnaturalizar paradigmas, pois o título que antecede a escrita da fundamentação teórica é "princípios suleadores", seguido da explicação de que o termo sulear, cunhado por Paulo Freire (STRECK; REDIN; ZITKOSKI, 2008), chama a atenção para as ideologias presentes no termo "nortear", ao se centrarem nas culturas euro-estadunidenses como modelos universais e normalizadores, em perspectiva colonialista (CANDAU, 2019).

Nesse sentido, inferimos que o uso do termo sulear também contribuiu para o processo de decolonialidade do currículo, que parte da premissa de que as manifestações corporais privilegiadas pelo currículo da Educação Física comumente estão baseadas nas culturas hegemônicas. Entretanto, apresentaremos, a seguir, tensões e desafios na utilização desse termo e, também, no próprio processo de tradução das perspectivas multiculturais decoloniais no desenvolvimento de pesquisa e de construção curricular, em contextos de formação continuada docente.

\section{Tensões e desafios: a tradução de perspectivas multiculturais decoloniais em processo de tessitura curricular}

A partir do exposto, cabe, neste ponto, a discussão de tensões no processo de tradução da perspectiva multicultural decolonial para a construção curricular no contexto da formação continuada docente, como na experiência que narramos neste artigo.

Uma tensão manifesta-se, por exemplo, com relação à perspectiva multicultural decolonial, visto que o próprio termo "sulear", mencionado anteriormente, ainda que relevante para a decolonialidade do currículo, por valorizar saberes do sul em contraposição àqueles hegemônicos eurocêntricos (CANDAU, 2019), corre, no entanto, o risco de reproduzir dicotomias tais como "sul-norte", desconsiderando processos de tradução e hibridização (BHABHA, 2015) inerentes aos cruzamentos culturais, sempre fluidos e impermanentes. 
Tais tensões de tradução de perspectivas multiculturais decoloniais para o chão da escola manifestam-se, ainda, na construção da subseção "Temas da Educação Física", consubstanciado, no corpo do documento produzido, na tabela a seguir:

Tabela 1 - Temas da cultura corporal escolhidos pelos estudantes

\begin{tabular}{|c|c|c|}
\hline \multicolumn{3}{|c|}{$\begin{array}{l}\text { Na lista abaixo estão relacionados temas do universo da Educação Física. Quais você gostaria de conhecer e } \\
\text { vivenciar nas suas aulas? (Marque quantos você quiser): }\end{array}$} \\
\hline Opçōes de resposta & $\begin{array}{l}\text { Percentual de } \\
\text { respostas }\end{array}$ & $\begin{array}{l}\text { Frequência } \\
\text { absoluta }\end{array}$ \\
\hline Esportes convencionais (futebol, basquete, handebol e voleibol) & $66,4 \%$ & 1141 \\
\hline $\begin{array}{l}\text { Atividade Física e saúde (ginástica de academia, musculação, corrida de rua, treinamento } \\
\text { funcional, Pilates@i Crossfit@ etc.). }\end{array}$ & $62,5 \%$ & 1073 \\
\hline Lutas não brasileiras (judô, jiu-jitsu, karatê, kung fu, taekwondo, esgrima, MMA etc.) & $57,4 \%$ & 986 \\
\hline $\begin{array}{l}\text { Jogos e brincadeiras populares (piques em geral, peteca, corda, pique bandeira, taco, } \\
\text { queimado etc.) }\end{array}$ & $57,2 \%$ & 982 \\
\hline Esportes de aventura e atividades radicais (alpinismo, parkour, slackline etc.) & $55,9 \%$ & 960 \\
\hline Natação (aprendizado dos quatro nados: crawl, peito, costas e borboleta) & $53,3 \%$ & 916 \\
\hline Atividades aquáticas (polo aquático, nado sincronizado, hidroginástica etc.) & $53,1 \%$ & 912 \\
\hline Esportes de raquete (tênis, squash, badminton, tênis de mesa, frescobol etc.) & $51,4 \%$ & 883 \\
\hline Danças não brasileiras (hip-hop, rap, charme, salsa, zouk, balé, dança do ventre etc.) & $47,9 \%$ & 823 \\
\hline Ginásticas (ginástica rítmica, ginástica artística, acrobática, de trampolim) & $47,3 \%$ & 812 \\
\hline Danças brasileiras (funk carioca, samba, forró, axé, frevo, danças folclóricas etc.). & $45,5 \%$ & 782 \\
\hline Lutas brasileiras (capoeira, lutas indigenas etc.) & $44,5 \%$ & 764 \\
\hline Jogos eletrônicos (Nintendo wii, Xbox, PS4, DS etc.). & $44,4 \%$ & 762 \\
\hline $\begin{array}{l}\text { Conhecimento sobre o corpo (aspectos anatômicos, fisiológicos, nutricionais, } \\
\text { psicológicos, distúrbios alimentares, de imagem e socorros de urgência aplicados à } \\
\text { atividade fisica etc.) }\end{array}$ & $41,9 \%$ & 720 \\
\hline Práticas corporais alternativas (tai chi chuan, ioga etc.) & $41,7 \%$ & 716 \\
\hline Esportes individuais (Atletismo, golfe etc.) & $40,3 \%$ & 692 \\
\hline Atividades circenses (acrobacias, malabarismo, contorcionismo etc.) & $38,5 \%$ & 661 \\
\hline Esportes não convencionais (rugby, Tchoukball, corfebol, hóquei, futvolei etc.) & $37,6 \%$ & 646 \\
\hline Meditaçōes (Meditação Laica Educacional®) etc.) & $37,1 \%$ & 637 \\
\hline Jogos de Tabuleïro (xadrez, dama, war etc.) & $33,8 \%$ & 581 \\
\hline Jogos Cooperativos (futpar, volençol, dança da cadeira cooperativa etc.) & $29,0 \%$ & 498 \\
\hline Jogos de mesa (cartas, botão, pega varetas etc). & $28,5 \%$ & 490 \\
\hline Total de respondentes & 1718 & 1718 \\
\hline
\end{tabular}

Fonte: Colégio Pedro II (2017, p. 256).

Essa tabela apresenta o resultado de uma consulta feita aos estudantes, que buscou valorizar seus interesses sobre as "[...] manifestações da cultura corporal que gostariam de vivenciar nas aulas de Educação Física escolar [...]" (COLÉGIO PEDRO II, 2017, p. 256). Todavia, os próprios sujeitos que participaram da autoria dessa construção curricular acabaram por reconhecer, de forma indireta, uma limitação e contradição com relação à perspectiva multicultural decolonial do currículo, ao fazerem a seguinte ressalva:

Vale ressaltar, no entanto, as limitações deste levantamento, na medida em que alcançou apenas uma parcela do universo discente. Por outro lado, a partir de uma 
noção de cultura dinâmica que é reproduzida, produzida e ressignificada constantemente, o uso dessas informações para a escolha de temáticas a serem desenvolvidas durante as aulas deve ser feito complementarmente ao mapeamento da cultura corporal da comunidade e de outras estratégias que podem ser usadas para conhecer, mais a fundo, as práticas corporais e interesses dos estudantes. Do contrário, poder-se-ia incorrer no erro de cristalizar e naturalizar experiências e identidades que, em si, são fluidas e cambiantes (COLÉGIO PEDRO II, 2017, p. 257).

A partir dos dados, observa-se que o documento, de certo modo, tangencia a preocupação multicultural decolonial e as sensibilidades pós-estruturais, no sentido de não cristalizar ou fixar sentidos do currículo e das próprias identidades, relativizando o uso da tabela de temas e caracterizando-a como limitada. A sentença final do excerto acima parece reconhecer, de forma clara, a fluidez e a provisoriedade de discursos curriculares e de identidades culturais (IVENICKI, 2018; LOPES, MACEDO, 2011; MACEDO, 2006), confirmando os impactos da ação de tessitura curricular sobre os discursos produzidos, nesse processo de construção curricular.

Tais preocupações também estiveram presentes quando o documento produzido sugeriu que outros encaminhamentos pudessem ser dados, por exemplo o mapeamento da cultura corporal, que visa reconhecer as manifestações corporais que estão presentes tanto no espaço da escola como no universo cultural mais amplo, podendo ser feito, também, por um levantamento dos conhecimentos que os estudantes têm sobre determinada prática corporal (NEIRA, 2011). Dessa forma, para além do uso da tabela de escolha temática presente no currículo, o mapeamento da cultura corporal poderia favorecer "captura" mais próxima das nuances próprias da dinamicidade de identidades culturais e representações que fluem em cada comunidade escolar.

Entretanto, neste ponto, podemos identificar a tensão mais forte na tradução de perspectivas multiculturais decoloniais e pós-estruturais na construção coletiva de currículos, no chão da escola, como resultado de projetos de extensão e de pesquisa envolvendo universidade e formação continuada de professores. Por um lado, logramos incorporar a defesa de ações multiculturais decoloniais de valorização da diversidade cultural, de desafio a preconceitos, de problematização de binômios e dicotomias que desconhecem processos de hibridização e tradução cultural.

Por outro lado, o desafio a documentos que acabam por fixar sentidos do currículo, com nossa defesa da provisoriedade e da transitoriedade desses sentidos, encontra pontos de contradição, na medida em que temas curriculares são requisitados, no processo de tessitura curricular. De fato, a partir do momento em que os sujeitos da pesquisa buscam a inclusão das vozes dissonantes e plurais e que tais vozes solicitam a elaboração de um documento curricular, observamos que a essencialização e a fixação de sentidos curriculares acabam por ocorrer, em algum ponto da ação realizada.

Analisar se os participantes buscaram contornar tal tensão foi uma preocupação da pesquisa, o que foi conseguido, ainda que parcialmente, pelo fato de a construção curricular 
ter apresentação de indicativos e não de temas fechados e de ter suscitado sensibilidades quanto à diversidade cultural, à provisoriedade e fluidez dos sentidos dos discursos curriculares e das identidades, bem como pela valorização da alteridade e dos saberes não hegemônicos, como ficou claro nos excertos do documento produzido, apresentados anteriormente no presente artigo.

Preferimos, pois, compreender a fixidez como essencialização estratégica, na produção de documento exigido pela identidade institucional, sem a imposição de nosso referencial sobre os atores do campo. Nesse sentido, compreendemos que o presente estudo poderia ajudar-nos a pensar tanto nos desafios de não hegemonização de nossas perspectivas pósestruturais e decoloniais quanto, ao mesmo tempo, realizar o compromisso com o desafio a visões essencializadas das identidades e dos discursos que afirmam, como universais, saberes que são, tão somente, hegemônicos e colonialistas, inclusive no campo da Educação Física, foco do presente estudo. Se conseguimos alcançar tal compromisso na experiência em curso, reconhecemos que outros estudos empíricos poderiam enriquecer e tensionar tais perspectivas, para o avanço da pesquisa multicultural decolonial sobre currículos de educação e de formação de professores.

\section{Ressonâncias multiculturais decoloniais nas identidades docentes}

Ao longo da trajetória de tessitura curricular, certamente aqueles que contribuíram para sua tessitura não continuaram os mesmos. Cada um carregou um pouco do outro e dessa experiência para a vida. O currículo tecido esteve em constante transformação porque foi impactado por aqueles que o teceram, ao mesmo tempo, ao ser tecido provocou transformações mais ou menos significativas nas identidades docentes. Pudemos compreender melhor as ressonâncias da tessitura curricular nas identidades docentes ao entrevistar seis dos 21 docentes que participaram dessa trajetória. Dentre esses, a professora Jordana apresentou a relação da sua participação na construção curricular com as influências dessa experiência em sua formação que achamos importante destacar. Disse ela:

E acho que a experiência de construí-lo me deu subsídios pra conseguir rever e construir práticas [...] eu não saio mais de uma leitura fria do documento. Aquele documento, na verdade, é parte de um processo que eu vivi, e que ao longo desse processo eu também fui me construindo, o currículo estava se construindo e eu acho que eu estava me reconstruindo junto com ele, e aí esse processo torna mais fácil o que vem depois do documento pronto (Jordana, entrevista realizada em 19/09/2018).

A nosso ver, essa fala apresenta de maneira significativa a relação entre a construção curricular e a formação continuada dos professores participantes, pois, quando esses se propuseram participar da elaboração curricular, chegaram com suas experiências, valores, certezas, dúvidas e identidades que aos poucos entraram em confluência e confronto com 
outras identidades e representações institucionais, discentes e docentes, possibilitando uma permanente desconstrução e reconstrução de si, e a composição de novas identidades docentes. Para a professora, construir o currículo significou construir-se também ao longo da trajetória curricular, o que facilitou sua apropriação do documento porque esse representou o que ela viveu.

Destacamos também os efeitos que os debates entre as diferenças podem gerar quando docentes permitem-se compartilhar experiências, reflexões e conhecer outras representações, perspectivas e ações didáticas ao expor suas experiências a outras identidades docentes, Desse modo, a aprendizagem docente alça um patamar de ação colaborativa e construção conjunta nas comunidades de aprendizagem docente, tornando-a mais plural e aberta à diferença.

Identificamos a potencialidade dessas experiências, na medida em que, no contexto das entrevistas, buscamos perceber se os/as professores/as entrevistados/as haviam identificado alguma influência da sua participação nesse processo em sua atuação na sala de aula. Chamou-nos a atenção a fala do professor Reginaldo, destacado anteriormente pela sua resistência às teorias pós-críticas da Educação Física, que disse o seguinte:

Tinham pessoas muito fortes no grupo, né? Pessoas com falas muito fortes. Isso fez com que várias questões me forçassem uma reflexão em relação a pontos que eu tinha, assim, bem já enraizados e tudo mais. Foi muito interessante. Chamo atenção de uma pessoa especificamente, a Jordana. Uma pessoa que tinha uma argumentação teórica bastante significativa em relação à sala de aula. Isso me marcou legal, porque me fez refletir sobre algumas questões que eu tenho alguma dificuldade nas aulas e pude fazer um contraponto em relação a isso e foi bastante interessante (Reginaldo, entrevista realizada em 02/10/2018).

A fala do professor Reginaldo permite-nos constatar o quanto debates abertos à diferença podem contribuir para gerar ao menos ranhuras nas estruturas das nossas "certezas" pedagógicas. A partir dessa fala, inferimos, também, que experiências de aprendizagem docentes multiculturalmente orientadas podem contribuir para romper com uma espécie de daltonismo cultural, termo cunhado por Stoer e Cortesão (1999) para caracterizar a tendência em homogeneizar culturas e identidades, e por isso ficam impedidos de reconhecer o arco-íris de culturas presente na escola. A decolonialidade do currículo multicultural de Educação Física manifesta-se, portanto, tanto na produção do documento curricular como nas falas dos professores participantes do processo, desestabilizando, como propõe Miranda (2013), visões hegemônicas, colonialistas, sexistas, racializadas do conhecimento na área.

Sensibilizar docentes para a diversidade na educação, na perspectiva multicultural decolonial permite a problematização de estereótipos e preconceitos que tensionam visões plurais. No entanto, tais ações dentro de uma perspectiva crítica precisam superar atitudes meramente condenatórias "[...] e resgatar o espaço intraescolar para viabilizar práticas pedagógicas imbuídas por expectativas que celebrem a diversidade cultural, ao invés de 
abafá-la" (CANEN, 2001, p. 208). Uma alternativa possível seria o desenvolvimento de formações docentes que sensibilizem professores/as para a pluralidade cultural e que propiciem encaminhamentos didático-pedagógicos coerentes com essa perspectiva, construindo cartografias decoloniais propiciadoras de formas alternativas de compreensão do currículo para a diversidade e para o desafio à colonialidade de saberes.

Defendemos que o processo de construção curricular da Educação Física aproximou-se dessa perspectiva, pois, após o período de 12 meses de construção curricular em que 21 docentes estiveram juntos estudando, debatendo e pesquisando currículo, algumas falas das entrevistas apresentaram para nós impactos multiculturais significativos nas vidas de docentes como a professora Silvana, que afirmou ter conseguido apurar mais o seu olhar para as diferenças ao constatar que, durante o processo de construção curricular, havia se percebido "negligente" ao lidar com alguns estudantes. Diante dessa constatação da professora Silvana, questionamos se, em alguma medida, a experiência de construção curricular havia contribuído para que ela superasse o que ela denominou de "negligência" no trato com as diferenças. Ela nos respondeu da seguinte maneira:

Eu acho que a primeira função foi me enxergar nesse processo, porque, às vezes, você não enxerga. Por exemplo, eu tive aquele aluno, Jairo, que teve muitos problemas comigo porque ele disse que eu era muito preconceituosa com ele, que eu discriminava ele. Porque eu cobrei muito dele. Eu cobrei. Acho que eu teria uma postura, hoje, um pouco mais diferente com ele. Eu só percebi que ele começou a me respeitar quando eu tive uma atitude. Eu o chamei pra perguntar o que ele gostava de fazer. Ele me falou que participava da Casa do Jongo ${ }^{4}$. Disse que era umbandista. Eu falei pra ele: "Poxa, me conta um pouquinho da sua história, o que é que você faz lá? Você não pode postar umas fotos suas pra mim pelo Facebook?". Aí ele postou. Aí eu falei assim: “Será que se eu chamasse você pra apresentar pra uma turma, você viria?". Depois disso, eu abri um campo de possibilidades com ele que eu não sabia disso [...]. Eu estava muito mais preocupada com a assiduidade dele, com a tentativa de trazer ele pra minha aula, só que eu não encontrei o caminho, só encontrei o caminho depois. [...] diz que estudo amplia a nossa visão. Eu acho que, assim, influenciou na minha tentativa? Claro que influenciou. Influenciou assim, de estar querendo buscar nele alguns elementos que ele [...] tem identidade pra eu conseguir chegar a ele, e que é uma identidade que não é minha. Então, pra mim, era difícil, talvez, procurar isso nele e depois isso ter como um insight... [...] Porque era muito mais fácil eu criticar e querer que ele ficasse dentro dos meus modelos (Silvana, entrevista realizada em $02 / 10 / 2018$ ).

Esse exemplo é muito rico por nos possibilitar várias oportunidades de reflexão à luz da perspectiva multicultural decolonial. A professora ressalta que inicialmente precisava enxergar-se agindo com preconceito, pois, segundo ela, "às vezes, você não se enxerga". A metáfora da visão utilizada pela professora permite-nos associar que inicialmente ela estava imersa numa espécie de visão colonialista, que a impedia de reconhecer as diferenças étnicas, 
de gênero, sexuais, religiosas etc. do estudante e não colocá-las em evidência em suas aulas (CANDAU, 2018). Professora Silvana assumiu ser mais fácil criticar e querer que o estudante se adequasse aos seus modelos. Com isso, reconhecemos traços do multiculturalismo assimilacionista (CANDAU, 2011), uma vez que queria impor padrões de comportamentos segundo seus referenciais, ignorando as características diferentes do estudante.

Candau (2018, p. 230) afirma que professores/as acometidos pelo daltonismo cultural e por visões colonialistas do saber têm dificuldade de valorizar as diferenças em sala de aula, também por "considerar que a maneira mais adequada de agir é centrar-se no grupo "padrão", acabando por reproduzir as atividades de ensino utilizadas para lidar com esse grupo "padrão", visibilizando estudantes que estão à margem desse grupo. Essa ação provoca silenciamentos e resistências, como aconteceu com o Jairo.

No entanto, com base nas reflexões da comunidade de aprendizagem docente que havia vivenciado, a professora Silvana se sentiu motivada a conversar com Jairo e conhecer sua história, suas origens, suas identidades culturais. Foi quando o estudante demonstrou seu interesse por Jongo e sua filiação religiosa à umbanda. Nesse momento, ao mesmo tempo que estava superando seu daltonismo cultural e a visão colonialista curricular, a professora Silvana abria um espaço para a sua tomada de consciência da construção da identidade cultural do Jairo, num plano pessoal e na relação dele com processos socioculturais.

Nesse sentido, ambos estavam se permitindo "reconhecer nossas identidades culturais" (CANDAU, 2011), adquirindo sensibilidades multiculturais decoloniais. Em seguida, a professora convidou-o para apresentar um pouco da sua cultura para outros estudantes. Com essa atitude, tanto valorizou a identidade cultural de Jairo quanto tornou sua aula multiculturalmente orientada ao permeá-la por elementos multiculturais decoloniais, valorizando identidades culturais plurais, não hegemônicas, como a do estudante Jairo, marcadamente caracterizada pelas culturas africanas.

Dessa forma, consideramos que esse relato de experiência permite-nos perceber o quanto a vivência de uma comunidade de aprendizagem docente multicultural pode oferecer subsídios para que professores/as assumam posturas sensíveis à diversidade cultural perante sua prática profissional e seus estudantes.

\section{Conclusões}

Ao buscarmos compreender como uma experiência de construção curricular se constituiu num processo de formação continuada imbuído de perspectiva multicultural decolonial com vistas à construção de identidades docentes valorizadoras da diversidade cultural, concluímos que a participação das diferenças, nesse fórum de construção curricular, contribuiu para a pluralidade de visões sobre as temáticas abordadas e, consequentemente, para a constituição de identidades docentes mais sensíveis à diversidade cultural presente na escola.

Ao mesmo tempo, estamos conscientes dos dilemas relativos à construção curricular multicultural na perspectiva decolonial. Dentre tais dilemas, apontamos o fato de ter sido 
requisitada a elaboração de um currículo, de uma proposta curricular para o colégio. Tal perspectiva traz, em si, tensões com relação a perspectivas multiculturais decoloniais curriculares, uma vez que implica em uma intencionalidade de fixidez de sentidos contrária a visões que apontam a provisoriedade e a diversidade de discursos curriculares que desafiam sua pseudouniversalidade. Como lidar com tais tensões e, ao mesmo tempo, como tornar a construção curricular em tela em experiência de tessitura que pudesse sensibilizar os atores educacionais quanto a essas mesmas tensões?

Tais questões revelam os dilemas de tradução de perspectivas multiculturais decoloniais para ações extensionistas e de pesquisa, da universidade, nas suas relações com o chão da escola, em experiências de construção curricular. O estudo nos tornou humildes, levando-nos a compreender que, em algum momento, uma perspectiva de essencialização "estratégica" acaba por se impor, de modo que se produza algum documento a que fomos chamados a desenvolver, junto a atores educacionais. O que procuramos realizar, nessa experiência, talvez tenha sido contribuir para a sensibilização quanto ao aspecto essencializador ali presente, desconstruindo uma visão universalizante e colonialista dos discursos curriculares.

Portanto, tentamos resolver provisoriamente tal dilema visto que, por um lado, procuramos valorizar as vozes de todos, com a participação das diferenças sem distinção de pessoas mais ou menos alinhadas com os pensamentos dos coordenadores do processo, e por outro, pela forma como lidamos com divergências surgidas em virtude das possíveis ênfases entre perspectivas curriculares, o que permitiu aos participantes um espaço aberto para colocarem seus argumentos por meio da negociação cultural.

Igualmente significativo foi quando, na leitura coletiva, surgiu o debate a partir do questionamento a respeito dos discursos normativos curriculares imbuídos na listagem de temáticas. Essa sensibilidade possibilitou aprofundarmos os debates de gênero, dentro de uma perspectiva multicultural decolonial, desvelando e problematizando discursos sexistas no currículo da Educação Física, o que permitiu ao grupo analisar relações colonialistas de poder entre as identidades e problematizar as construções históricas de preconceitos e de valorização diferencial dos saberes.

$\mathrm{O}$ fato de o documento analisado não ter definido taxativamente temas específicos por anos de ensino, mas, ao contrário, apresentar algumas indicações e recomendações, pode, talvez, ser indicativo de possibilidades futuras de valorização das experiências cotidianas, escorregadias, a que se referem Ranniery e Macedo (2018), ainda que reconheçamos que representou um momento de fixidez de sentidos, requisitado pelos atores educacionais do campo empírico onde se realizou a pesquisa.

Certamente, essa trajetória gerou ressonâncias multiculturais decoloniais na escrita curricular, o que problematizou currículos anteriores e propôs a desnaturalização de termos baseados em paradigmas universais e normalizadores a partir do termo sulear, igualmente complexo e talvez essencializador, porém indicativo de sensibilidade decolonial, em gênese, sobre a Educação Física escolar.

Outras ressonâncias multiculturais decoloniais dessa experiência de tessitura curricular foram constatadas em professores que se perceberam em processo de construção na medida em que o currículo também se constituía, ao provocar desestabilizações em concepções 
docentes anteriormente "enraizadas", colonialistas, assim como por ter provocado rupturas com comportamentos anteriormente preconceituosos com relação aos estudantes, abrindo possibilidades multiculturais sensíveis às diferenças e a valorização de culturas subalternizadas.

Por último, a partir de uma noção de cultura como processo, identificamos encaminhamentos que dialogaram com a fluidez e dinamicidade das diversas identidades escolares. Dessa forma, é possível concluir que experiências de aprendizagem docente como essas podem contribuir para forjar identidades docentes mais sensíveis às opiniões divergentes e abertas às perspectivas pedagógicas multiculturais decoloniais, ainda que o caminho para a tradução dessas perspectivas nas experiências de construção curricular coletiva seja provisório e requisite, cada vez mais, estudos que possam contribuir para a pesquisa na construção de currículos multiculturais decoloniais, em experiências concretas e cotidianas, nas instituições educacionais brasileiras.

\section{Notas:}

1. Departamento de Educação Física.

2. Todos os nomes são fictícios para preservar o anonimato dos participantes.

3. Os Jogos Intercampi são jogos que acontecem anualmente no âmbito do Colégio Pedro II e compõem inúmeras competições desportivas promovidas pelo Departamento de Educação Física para todos os estudantes do Colégio.

4. Casa cultural situada no Rio de Janeiro que, dentre outras ações, promove a valorização do Jongo, dança brasileira de origem africana.

\section{Referências}

BHABHA, H. K., FOREWORD. In: WERNER, P.; MODOOD, T. (eds.), Debating Cultural Hybridity: multicultural identities and the politics of anti-racism. London,

UK: Zed Books, 2015.

CANDAU, V. M. F. Multiculturalismo e Educação: desafios para a prática pedagógica. In: MOREIRA, A. F. B.; CANDAU, V. M. (orgs.). Multiculturalismo: diferenças culturais e práticas pedagógicas. 7. ed. Petrópolis, RJ: Vozes, 2011. p. 13-37.

CANDAU, V. M. F. Sociedade Multicultural e Educação: tensões e desafios. In: CANDAU, V. M. F. (org.). Didática crítica intercultural: aproximações. Petrópolis, RJ: Vozes, 2012. p. 19-54.

CANDAU, V. M. Interculturalidade e Cotidiano Escolar. In: CANDAU. V. M. (org.). Didática: tecendo/reinventando saberes e práticas. Rio de Janeiro: 7 Letras, 2018. p. 220-235.

CANDAU, V. M. F. Pedagogias e Pesquisas na Perspectiva Decolonial. Sessão Especial, In: 39 ${ }^{\mathbf{a}}$ Reunião Anual da ANPEd: Educação Pública e Pesquisa: ataques, lutas e resistências, Niterói: Universidade Federal Fluminense, 2019.

CANEN. A.; MOREIRA, A. F. B. Reflexões sobre o Multiculturalismo na Escola e na Formação Docente. In: CANEN, A.; MOREIRA, A.F.B. (orgs.). Ênfases e omissões no currículo. Campinas, SP: Papirus, 2001. p. $15-44$. 
CANEN, A.; XAVIER, G. P. de M. Formação continuada de professores para a diversidade cultural: ênfases, silêncios e perspectivas. Revista Brasileira de Educação, Rio de Janeiro, n. 48, p. 641-663, set./dez. 2011.

COCHRAN-SMITH, M.; LYTLE, S. L. Teacher learning communities. In: GUTHRIE, J. (ed.). Encyclopedia of Education. 2. ed. New York: Macmillan. 2002.

COLÉGIO PEDRO II. Departamento de Educação Física. In: COLÉGIO PEDRO II. Projeto Político Pedagógico Institucional Colégio Pedro II. p.234-260. 2017. Disponível em: http://www.cp2.g12.br/images/comunicacao/2018/JUL/PPPI\%20NOVO.pdf Acesso em: 22 dez. 2018.

DENZIN, N.; LINCOLN, Y. O planejamento da pesquisa qualitativa: teorias e abordagens. 2. ed. Porto Alegre: Artmed, 2010.

DESLANDES, S. F. O projeto de pesquisa como exercício científico e artesanato intelectual. In: MINAYO, M.C. de S.; DESLANDES, S. F.; GOMES, R. (orgs.). Pesquisa social: teoria, método e criatividade. 31. ed. Petrópolis, RJ: Vozes, 2012, p. 31-60.

GIL. A. C. Como elaborar projetos de pesquisa. 4. ed. São Paulo: Atlas, 2002.

GOMES, R. Análise e interpretação de dados de pesquisa qualitativa. In: MINAYO, M. C. (org.). Pesquisa social. Teoria, método e criatividade. 29. ed. Petrópolis, RJ: Vozes, 2010. p. 79-108.

IVENICKI, A. Multiculturalismo e Formação de Professores: dimensões, possibilidades e desafios na contemporaneidade. Ensaio. Avaliação e Políticas Públicas em Educação, v. 26, 2018 p. 1151-1167.

IVENICKI, A.; XAVIER, G. P. M., Diversidade e Formação de Professores na Educação Básica: contribuições do multiculturalismo e da pesquisa-ação. In: RIOS, J. A. V. (org.). Diferenças e desigualdades no cotidiano da educação básica. Campinas: Mercado das Letras, 2017. p. 57-70. v. 1.

JANOÁRIO, R. Diálogos Interculturais. Rio de Janeiro: Ayvu, 2018.

LOPES, A. C.; MACEDO, E. Teorias de currículo. São Paulo: Cortez, 2011.

LOPES, A. C.; OLIVEIRA, A. L. A. R. de M.; OLIVEIRA, G. G. S. de. Apresentação: gênero e sexualidade na educação brasileira- tensões, deslocamentos e horizontes. In: LOPES, A. C.; OLIVEIRA, A. L. A. R. de M.; OLIVEIRA, G. G. S. de, (orgs.). Os gêneros da escola e o (im)possível silenciamento da diferença no currículo. Recife: Ed. UFPe, 2018. p. 7-20.

MACEDO, E. Currículo como espaço-tempo de fronteira curricular. Revista Brasileira de Educação, v. 11, n. 32, p. 285-296, 2006.

MILLER, J. L. Curricular Multiplicities and Constant Cultural Translations. In: Roundtable Differing Differences: transnational curriculum spaces and inquiries in post-truth times, Division B, Curriculum Studies, 2019 AERA Annual Meeting, 5-9 de Abril, Toronto, Canadá, 2019.

MINAYO, M. C. de S. Técnicas de Pesquisa: entrevista como técnica privilegiada de comunicação. In: MINAYO, M.C. de S. O desafio do conhecimento: Pesquisa qualitativa em saúde. 12. ed. São Paulo: Hucitec, 2010. p. 261-297.

MIRANDA, C. Currículos Decoloniais e Outras Cartografias para a Educação das Relações Etnicorraciais: desafios político-pedagógicos frente à Lei 10639/2003, Revista da ABPN, v. 5, n. 11, p. 100-118, 2013.

MOREIRA, A. F. B.; CANDAU, V. M. (orgs.). Multiculturalismo: diferenças culturais e práticas pedagógicas. 7. ed. Petrópolis: Vozes, 2011. p. 13-37.

NEIRA. M. G. Educação Física: Coleção A reflexão e a prática no ensino. São Paulo: Blucher, 2011. v. 8.

NEIRA, M. G. O currículo cultural da Educação Física: uma resposta aos dilemas da contemporaneidade. Revista Linhas, v. 16, n. 31, p. 276-304, 2015.

NEIRA, M. G.; NUNES, M. L. F. Educação Física, currículo e cultura. São Paulo: Phorte, 2009.

RANNIERY, T.; MACEDO, E. Políticas do vivível: diferença, teoria e democracia por vir. In LOPES, A. C.; OLIVEIRA, A. L. A. R. de M.; OLIVEIRA, G. G. S. de (orgs.). Os gêneros da escola e o (im)possível silenciamento da diferença no currículo. Recife: Ed. UFPE, p. 21-50, 2018. 
SILVA, Tomaz Tadeu. Documentos de identidade: uma introdução às teorias do currículo. 3. ed. Belo Horizonte: Autêntica, 2011.

STOER, S.R.; CORTESÃO, L. "Levantando a Pedra" - Da pedagogia inter/multicultural às políticas educativas numa época de transnacionalização. Porto: Afrontamento. 1999.

STRECK, D.; REDIN, E.; ZITKOSKI, J. J. (orgs.). Dicionário Paulo Freire. Belo Horizonte: Autêntica, 2008.

YIN, R. K. Estudo de caso: planejamento e métodos. Tradução de Daniel Grassi. 2. ed. Porto Alegre: Bookman, 2001.

\section{Correspondência}

Fabiano Lange Salles: É mestre e doutor em Educação pela Universidade Federal do Rio de Janeiro (2014, 2019). É graduado em Licenciatura em Educação Física pela Universidade Federal do Rio de Janeiro (2003). É professor do Ensino Básico do Colégio Pedro II. Tem publicações na área de Educação Física escolar com ênfase em multiculturalismo, currículo, formação de professores e educação especial e inclusiva.

E-mail: fabianols@globo.com

Ana Ivenicki: É PhD em Educação pela University of Glasgow. É professora emérita da Universidade Federal do Rio de Janeiro/UFRJ, lotada na Faculdade de Educação. É pesquisadora 1A do CNPq. Possui publicações na área de Multiculturalismo, Currículo e Formação de Professores.

E-mail: aivenicki@gmail.com

Texto publicado em Currículo sem Fronteiras com autorização dos autores. 